\title{
SIGNIFICAÇÕES IMAGINÁRIAS DO HUMOR NOS QUADRINHOS DE CONCEIÇ̃̃O CAHÚ
}

\author{
IMAGINARY MEANINGS OF HUMOR IN THE CONCEIÇÃO CAHÚ'S COMICS
}

\begin{abstract}
RESUMO
O artigo disserta acerca das significações imaginárias do humor no quadrinhos Uma História de Amor, premiada no 19ํㅡㄴ Salão de Humor de Piracicaba, de autoria de Conceição Cahú que assim como outras autoras foram esquecidas entre os pesquisadores e são desconsideradas como pioneiras em representações gráficas sequenciais com uma maneira peculiar de construção do humor e seu reflexo no cotidiano da sociedade. Conceição Cahú apresenta em sua obra um humor calcado no empoderamento social, na sexualidade e em sua própria biografia, com uma estética narrativa que ressoa entre artistas do mais variados gêneros. A nossa hipótese é que Conceição Cahú aponta em um discurso humorístico com traços ingênuos, grotescos e com diálogo de contraponto constante com os estereótipos femininos criados por autores masculinos. Apresentamos uma introdução à autora, contexto social do qual se desenvolve como quadrinista e o legado criativo para as histórias em quadrinhos.
\end{abstract}

Palavras-Chave: Histórias em quadrinhos. Humor. Feminino. Imaginário. Cotidiano.

\begin{abstract}
The article discusses the imaginary meanings of humor in the comic A History of Love, awarded at Piracicaba's 19th Humor Hall, by Conceição Cahú, who, like other authors, have been forgotten among researchers and are disregarded as pioneers in sequential graphical representations with a peculiar way of constructing humor and its reflection in the daily life of society. Conceição Cahú presents in his work a humor based on social empowerment, sexuality and his own biography, with an aesthetic narrative that resonates between artists of the most varied genres. Our hypothesis is that Conceição Cahú points out in a humorous discourse with naive, grotesque traits and with constant counterpoint dialogue with the female stereotypes created by male authors. We present an introduction to the author, social context of which develops as a comic book and the creative legacy for comic books.
\end{abstract}

Keywords: Comic books. Humor. Female. Imaginary. Daily.

Dr. Alberto Ricardo Pessoa

Pós Doutorado em Sociologia. Professor Adjunto do Programa de Mestrado em Comunicação da UFPB.

E-mail: albertoricardopessoa@gmail.com 


\section{Introdução}

1992. No centro de São Paulo um homem e uma mulher resolvem aproveitar o horário de almoço para ir num motel. Após as preliminares o homem esboça a penetração quando a mulher prontamente grita:

- Esquecemos a camisinha! Sem camisinha nada feito! Nada feito. Mesmo!

O homem chocado e nervoso com a reação da mulher, inicia um diálogo tenso:

- E você vem falar nisso só agora?

- Você também devia se lembrar disso!

- Vou lhe pegar na marra!

A mulher com semblante tranquilo, confiante e decidido, argumenta:

- Nem tente malandro! Fiz curso de capoeira! Sou cordão vermelho! Sem camisinha nada feito!

O homem, resignado e frustrado recebe a sugestão da mulher de ligar para o porteiro pedindo uma camisinha. O porteiro conversa em tom irônico e jocoso com o homem, oferecendo uma camisinha de segunda mão.

Após perceber a brincadeira, o homem resolve ir na farmácia comprar a camisinha, sem deixar de ameaçar violentar a mulher caso ela se insinue em demasia. O homem fala de forma contrariada:

- Vou sair, sob protesto mas vou sair! É isso que dá transar com mulher esclarecida! Volto já!

Essa introdução é a base da trama da história em quadrinhos Uma História de Amor de Conceição Cahú, publicada em 1992 e premiada como a melhor história em quadrinhos do $19^{\circ}$ Salão de Humor de Piracicaba.

Nos seus 45 anos de profissão, Conceição Cahú foi uma das poucas autoras de histórias em quadrinhos a ter uma produção profícua e reconhecida em um cenário profissional predominantemente masculino.

Essa hipótese é reforçada quando consideramos enquanto escopo a produção de mais de um século de histórias em quadrinhos e os poucos nomes de autoras em publicações, premiações e inclusive em pesquisas históricas, entendemos que há falta de publicações acerca da representatividade feminina histórica nos quadrinhos e dos próprios pesquisadores utilizarem autoras e seus trabalhos em artigos e respectivas análises. 
Hoje em dia é senso comum que o mundo dos quadrinhos é masculino. A loja de histórias em quadrinhos está repleta de garotos e homens que compram quadrinhos violentos com superheróis de rosto sombrio e muito musculoso e mulheres com seios grandes e improváveis. Uma menina ou uma mulher nessas histórias é uma raridade, e as histórias em quadrinhos de ou para mulheres e meninas são igualmente raras. A maioria das pessoas associa quadrinhos com garotos e super-heróis, acreditando que sempre foi a situação (Robbins, 2018: o1 Tradução nossa.)

Pesquisador reconhecido como referência nos estudos das histórias em quadrinhos como Daniele Barbieri não considerou as autoras em seu livro I linguaggi del Fumetto, de 1991. Uma constatação que exemplifica isso é que em seu estudo há 117 ilustrações, 12 lâminas e 30 referências bibliográficas e desse escopo apenas a historiadora Paola Pallottino com Storia dell'illustrazione italiana (1988) é citada.

Críticos também se esquecem do legado feminino nos quadrinhos. Franck Bondoux, diretor do Festival de Angoulême deu uma declaração em 2016 após ter o festival boicotado por artistas como Riad Sattouf, Joann Sfar, Milo Manara, Daniel Clowes, Chris Ware, Charles Burns, Pierre Christin, Etienne Davodeau, e Christophe Blain.

Parapiorarasituação, emumaentrevista notavelmenteequivocada, o diretor executivo do festival, Franck Bondoux, afirmou que havia uma razão muito simples para que nenhuma mulher fosse incluída entre os indicados. Não foi por discriminação, ele disse. Em vez disso, foi por falta de mulheres qualificadas. "O Festival gosta de mulheres, mas não pode reescrever a história dos quadrinhos", disse ele. Bondoux citou a história da arte como suporte. "Se você for ao Louvre", ele disse, "você encontrará poucas mulheres artistas". (McCubbin, 2018: o1 Tradução nossa.)

Este artigo se coloca em discordância com Franck Bondoux e se alinha com pesquisadores como Tom Spurgeon da qual entende que há um equívoco na abordagem de pesquisa em histórias em quadrinhos quando a ênfase é na análise do papel da mulher no desenvolvimento dessa linguagem.

Tom Spurgeon, o escritor da revista Comics Repórter e diretor executivo do Cartoon Crossroads Columbus, um festival de quadrinhos americanos, discordou do pronunciamento de Bondoux. "É muito fácil reescrever a história dos quadrinhos", disse Spurgeon. "Isso acontece o tempo todo. Você reescreve a história colocando pessoas nessas listas. A afirmação falha em Angoulême é um argumento cético e terrível de se fazer. Os jurados não foram sequer solicitados a analisar a história. Eles foram convidados a avaliar o presente. Zero por zo é uma leitura triste do presente. "(McCubbin, 2018: o1 Tradução nossa.) 
Este artigo não pretende ser uma introdução somente ao legado de Conceição Cahú, mas a própria participação das mulheres na criação das histórias em quadrinhos e sua contextualização sócio comunicacional.

Conceição Cahú foi uma artista completa na acepção da palavra e através de suas pinturas, charges de cunho político, cartuns com opiniões acerca de temas atemporais e fundamentais na nossa sociedade, caricaturas com uma técnica de bico de pena que hoje em dia é um ponto de referência entre artistas e quadrinhos publicados em diversos jornais, revistas, antologias e salões, foi capaz de apresentar uma visão pioneira acerca de empoderamento social, do qual pretendemos demonstrar aqui com a análise da história em quadrinhos Uma história de Amor.

\section{Conceição Cahú}

Conceição Cahú foi uma artista gráfica que inicia suas atividades artísticas na década de 70. Apesar de iniciar a carreira em Recife é em São Paulo que a autora começa a trabalhar em grandes editoras como a Abril e mais tarde em Jornais como a Folha de São Paulo, Jornal da Tarde, Gazeta Mercantil e Diário do Comércio Indústria \& Serviços.

Conceição Cahú trabalhou nos principais gêneros gráficos publicados em jornais e revistas no país. No recorte de nosso artigo, iremos apenas analisar o seu trabalho enquanto autora de histórias em quadrinhos, porém é importante ressaltar o seu escopo artístico nas áreas da ilustração, charge e cartum, uma vez que antes da artista, poucas mulheres possuem créditos em publicações.

As mulheres encontraram no universo das histórias em quadrinhos diversas dificuldades de inserção, tais como abster de ter seus nomes como autoras e trocar por pseudônimos, produzir material de direcionamento heteronormativo ou para uma formação estereotipada da mulher dona de casa, casada e uma predominância de personagens e histórias voltadas para o público masculino.

Esse fator faz com que os dados acerca das pioneiras das histórias em quadrinhos sejam difusos e até mesmo controversos, como podemos verificar ao longo deste artigo.

Um exemplo é a hipótese que existe acerca do criador do anti-herói Garra Cinzenta. A história foi desenhada pelo desenhista brasileiro mais relevante daquela época, Renato Silva e escrita por um discreto autor chamado Francisco Armond. Garra Cinzenta é considerada a primeira história brasileira a apresentar um antiherói como protagonista de uma série de histórias em quadrinhos.

(...) a primeira grande narrativa policial dos quadrinhos brasileiros, publicada originalmente em cem capítulos de uma página cada em A Gazetinha entre 1937 e 1939, permaneceu na obscuridade por décadas. O primeiro capítulo saiu na edição de número 235, de 27 de julho de 1937. E com um mistério adicional: 
ninguém sabe com certeza quem seria Francisco Armond. Todos os indícios sugerem que fosse a jornalista Helena Ferraz, mas ela nunca assumiu a autoria publicamente. (Souza, 2011: o8)

Trata-se de uma série que apresenta a essência do gênero Noir, com o cômico representado pelo grotesco e o humor negro. A violência e o fetiche sadomasoquista são elementos coadjuvantes mas fundamentais para o entendimento da trama, uma vez que os personagens principais são caracterizados assim.

Apesar de diversos indícios apontarem para a autora Helena Ferraz como a verdadeira criadora de Garra Cinzenta, não há como afirmar isso de forma categórica.

Quanto a ela nunca ter assumido tal autoria, a explicação estaria no fato de que havia não só o preconceito contra os quadrinhos, mas também o preconceito maior ainda contra mulheres que escrevessem tal coisa. (Souza, 2011: 25)

Uma antecessora de Conceição Cahú e que fez carreira como autora de histórias em quadrinhos, chargista, cartunista e caricaturista é Hilde Weber (1914-1994). Artista de origem alemã, trabalha no Brasil a partir de 1933 passa a colaborar em diversos jornais e revistas como Diários Associados, Folha de São Paulo, Manchete, O Cruzeiro e Noite Ilustrada.

Tanto Conceição Cahú quanto Hilde Weber possuem o escopo principal de sua carreira na imprensa com o uso do humor para contextualizar o momento político do país. No entanto, se Hilde Weber concentrou a produção de charges em torno do governo Vargas, Conceição Cahú se desenvolve enquanto artista no âmago da contracultura, o que faz com que a artista expressa um discurso autoral de contestação do lugar comum das histórias em quadrinhos heteronormativas.

\section{Contracultura e Influências}

Os autores de histórias em quadrinhos foram criadores que ao longo do tempo souberam se adaptar aos avanços tecnológicos, bem como escrever histórias, personagens e discorrer acerca de assuntos contemporâneos a sociedade. A contracultura trouxe publicações independentes e comercializadas pelos próprios autores. Assim, a produção de histórias em quadrinhos em pequenos meios, com a comercialização fora do contexto de grandes editoras, jornais ou sindicatos fez com que novos autores surgiram com propostas ousadas tanto na arte quanto no discurso. Segundo Mazur \& Danner (2014: 23)

Em 25 de fevereiro de 1968, Robert Crumb e Dana, sua mulher na época, começaram a vender exemplares de Zap Comix n.1 num 
carrinho de bebê pelas ruas de Haight Ashbury, em São Francisco. A alegre coleção de poucas páginas dos quadrinhos escandalosamente sem censura de Crumb foi um sucesso instantâneo entre moradores, hippies pós-Verão do Amor. Começava o Movimento Underground dos quadrinhos Norte-Americanos.

Escritoras, artistas e entusiastas passaram a criar conteúdo para histórias em quadrinhos e compartilhar em antologias e revistas. O fenômeno foi global e foi presente em diversos gêneros das histórias em quadrinhos. Dentro de um contexto alternativo, Conceição Cahú foi ilustradora e quadrinista na revista Nós Mulheres, da Associação de Mulheres.

No Comics Underground, histórias em quadrinhos produzidas nos Estados Unidos e publicadas de maneira independente, podemos observar o surgimento de autoras que, assim como Conceição Cahú passaram a escrever com base em seu imaginário criativo, histórias acerca do próprio cotidiano, com o humor ácido e estilo calcado no cartoon, que privilegia a distorção da forma para exagerar nos efeitos dramáticos da mensagem.

Diferente da maioria das autoras do Comics Underground, Conceição Cahú tinha um trabalho artístico de primor profissional, sendo inclusive, reconhecida como mestre na técnica do bico de pena, estilo bastante usado na época.

Não temos como afirmar se Conceição Cahú foi diretamente influenciada pelo movimento underground americano ou pelas suas autoras, mas a artista conviveu com quadrinistas brasileiros que construíram o gênero alternativo brasileiro, o udigrudi. dentre os principais artistas que Cahú tem contato, destacamos Henfil, da qual Waldomiro Vergueiro analisa ao citar Rozeny Silva Seixas (1996), pesquisadora da obra de Henfil:

Desenhados em estilo underground, as mensagens apresentadas nas histórias em quadrinhos e tiras diárias produzidas por Henfil eram extremamente cáusticas ao panorama social predominante, proporcionando aos leitores uma forma de compensação catártica em relação àquilo que eles viviam cotidianamente (2017: 118)

Outro artista que influencia Conceição Cahú é Carlos Zéfiro, pseudônimo de Alcides Aguiar Caminha (1921-1992). A artista cria Uma história de Amor no ano de falecimento de Zéfiro e o homenageia na primeira página da história, além de criar uma narrativa próxima as narrativas do autor, conforme iremos demonstrar na última parte do artigo.

(...) Carlos Zéfiro chegou a criar mais dequinhentas histórias. Dono de um traço bastante singular - ainda que com pouca sofisticação - , ele foi autor de histórias que atiçaram a imaginação de seus leitores. Suas obras eram em geral escritas em primeira pessoa, de 
forma a fazer com que o leitor - presumivelmente, alguém do sexo masculino - se identificasse com o protagonista. Mas ele também elaborou várias histórias em que o papel principal era reservado a uma mulher, que relatava aos leitores as suas aventuras, desventuras ou peripécias sexuais. (Vergueiro, 2017: 121)

A referida homenagem não é à toa. Autor dos chamados catecismos (livros artesanais impressos em máquinas de fotocópia de pequeno formato e tiragem) , Carlos Zéfiro foi um autor de quadrinhos pornográficos no período da ditadura entre 1964 e 1985.

\section{ANÁLISE DE UMA HISTÓRIA DE AMOR}

Uma História de amor foi exposta e premiada na 19ª edição do Salão de Humor de Piracicaba e não foi publicada em nenhuma antologia ou revista desde então. $\mathrm{O}$ gênero da história é o de humor e é um desdobramento narrativo comum no Brasil que são as Histórias em Quadrinhos curtas entre 01 a 05 páginas.

Esse formato se tornou popular no país por se tratar do principal meio de publicação entre autores nacionais em editoras. Autores nacionais na sua grande maioria eram publicados em editoras que não detinham direitos de histórias e personagens estrangeiros. A viabilização econômica para as revistas eram coletâneas com diversos autores, do qual o editor podia publicar sob diversas alegações, desde de propiciar uma divulgação do artista até justificar um pagamento, muitas vezes simbólico pela história.

Dito isso, iremos apresentar a história para a leitura na íntegra e depois iremos analisar os elementos de humor contidos no trabalho de Conceição Cahú.

Na primeira página a autora faz uma página de apresentação ao leitor, com a cidade em uma vista aérea, com os protagonistas da história e uma narrativa que propõe ao leitor a continuação da trama na segunda página. Para um leitor comum, sem repertório prévio, não dá para saber qual será o gênero da história, uma vez que os personagens são retratados sem distorções, exageros ou em uma situação de conflito.

Há consenso em toda a cena, tanto na paisagem quanto no diálogo do casal. A estética da página é idealizada e reforça estereótipos do belo ao leitor. Por fim, é uma história em quadrinhos que utiliza a cor não como meio de reforçar a sensação de realismo, mas como meio de comunicação. O vermelho que moldura o casal que está prestes a ter uma relação sexual é um exemplo do uso da cor como comunicação.

Para um leitor que possui conhecimentos acerca dos autores de histórias em quadrinhos a leitura possui outra interpretação, uma vez que a autora apresenta um discurso junto ao título da história do qual coloca a mulher como protagonista de sua história. Por fim, a menção à Carlos Zéfiro dá ao leitor uma dimensão do que a seguir, uma vez que Zéfiro é um ator de quadrinhos cômicos pornográficos. 
Em uma história curta, o ponto de conflito da história deve ser apresentado na primeira ou segunda página, uma vez que são poucas páginas para a história ter um desfecho ou uma situação de resolução de problema. Assim, Conceição Cahú estabelece um primeiro quadro de transição entre o belo e o grotesco e no segundo quadro propõe, por meio da deformação do cartoon a situação de conflito, reforçada pelos textos e seus conectivos como o balão de texto.

Aqui conhecemos a personalidade dos personagens e nesse momento o discurso de Cahú surge ao colocar no texto verbal e não verbal da mulher um arcabouço de emancipação e independência. Ao mesmo tempo, o homem enfrenta um processo de reconfiguração. Do homem bonito e educado surge um ser caricato, rude, machista e imaturo no que se refere a resolução de problemas.

Nas histórias em quadrinhos, a postura do corpo e o gesto têm primazia sobre o texto. A maneira como são empregadas essas imagens modifica e define o significado que se pretende dar às palavras. Por meio da sua relevância para experiência do leitor, podem invocar uma nuance de emoção e dar inflexão audível à voz do falante. (Eisner, 2010: 106)

Conceição Cahú utiliza de um recurso característico que convidar o leitor a ser protagonista da leitura ao determinar o próprio ritmo de leitura e assim da conversa entre protagonista e porteiro.

Na página 03 com a sequência de closeup na mulher até a cena se expandir ao apresentar ao leitor o clímax da história, com o susto da mulher ao perceber que algo aconteceu ao rapaz. Nesse contexto Conceição Cahú utiliza o recurso da onomatopéia para assim reforçar a concepção de que algo está acontecendo na rua.

Uma história em quadrinhos torna-se "real" quando o tempo e o timing passam a ser componentes ativos da criação. Na música ou em outras formas de comunicação sonora, em que se consegue ritmo ou "cadência", isso é feito com extensões reais de tempo. Nas artes gráficas, essa sensação é expressa por meio do uso de ilusões e símbolos e do seu ordenamento. (Eisner, 2010: 24)

Nessa página há a intersemiose entre o realista e o grotesco na representação gráfica dos personagens. $\mathrm{O}$ homem está menos estilizado que na página 02 e menos idealizado que na página o1, assim como ambos estão mais harmônicos do que na página o2 e ao mesmo tempo mais distantes que na página o1.

A página 04 apresenta um final conservador, tanto no texto verbal, não verbal e na composição narrativa, do qual destoa da história como um todo, mas que faz sentido dentro da trajetória criativa de Conceição Cahú. Os personagens deixam de ser caracterizados de maneira grotesca para uma estrutura mais naturalista e bela, o que remete à direção de arte da página o1. Aqui a protagonista cede lugar ao processo 
de reinvenção do personagem masculino e assim se alinhar ao imaginário e cotidiano comum a protagonista.

Ao estabelecermos uma relação de sentido entre o imaginário de Conceição Cahú e os quadrinhos, observamos algumas estratégias de discurso que propõe um humor feminino e distinto do humor masculino.

Ao analisarmos a evolução gráfica dos rostos dos personagens ao longo da narrativa iremos verificar que apenas o homem passa por um processo cômico de caracterizado pelo grotesco. A mulher possui poucas alterações e é desenhada com a estética do belo, com traços arredondados e delicados. Em uma história curta os rostos do personagens são essenciais para a compreensão da história.

Seu papel na comunicação é registrar emoções. Nessa superfície, o leitor espera que os elementos móveis revelem uma emoção é um ato como um advérbio da postura ou gesto do corpo. Graças a essa relação, a cabeça (ou rosto) é usada com frequência pelos artistas para expressar a mensagem inteira do movimento corporal. É a parte do corpo com a qual o leitor está mais familiarizado. (...) A partir da leitura de um rosto, as pessoas fazem julgamentos diários, arriscam o seu dinheiro, o seu futuro político e as suas relações sentimentais. (Eisner, 2010: 114)

O diálogo entre humor e imaginação de Conceição Cahú é sintetizado na forma em que a autora representa graficamente o pênis e a vagina das personagens. Enquanto a vagina da protagonista foi apresentada de forma discreta, remetendo a censura com braços, sombras e objetos escondendo o sexo da personagem, o pênis tem uma condição oposta.

O pênis é um personagem ativo na história e é uma imagem que desperta dualidade e simbolismo por meio da rítmica sexual.

De todos os elementos gráficos apresentados pela artista, o Pênis é o único que possui cor, linhas de expressão, ritmo de movimento e mesmo reconfigurado, seja embaixo de uma coberta ou no formato de uma camisinha o pênis comunica e se apresenta como um ser a parte dos dois personagens, do qual se posiciona como uma linha de humor da autora.

O tom jocoso com o pênis do personagem destoa do humor masculino contemporâneo a Conceição Cahú e demonstra que o gênero possui peculiaridades no que se refere a comunicação e humor.

\section{CONSIDERAÇÕES}

A observação da narrativa, concepção gráfica dos personagens, animação rítmica dos símbolos, a subversão do fálico e o conservadorismo social revelam o universo imaginário de Conceição Cahú nas histórias em quadrinhos. A protagonista 
empoderada, desejada e longe do estereótipo da garota frágil e sensível é colocada em justaposição com um personagem que passa por um chamado, enfrenta um desafio, entra em crise e sai reconfigurado como um novo homem que é capaz de se relacionar com uma mulher protagonista de suas ações.

O estudo de um fragmento da obra de Conceição Cahú não é capaz de avaliar o todo da carreira da quadrinista, mas abre um leque para a reflexão acerca da história das histórias em quadrinhos pelo viés das autoras, que é ofuscado pelos pesquisadores, críticos e até mesmo pelos próprios autores de histórias em quadrinhos. A impressão que esses pesquisadores passam é que as mulheres não produziram histórias ao longo da trajetória do desenvolvimento dessa linguagem, ou se produziu não foi um escopo relevante.

Ao apresentar a obra de Conceição Cahú como um exemplo do humor feminino nos quadrinhos no Brasil, desmistificamos esse pensamento e busca com isso um veio de pesquisa que até o momento é pouco explorado pelos pesquisadores de histórias em quadrinhos que é analisar as biografias dessas autoras.

Não se trata de um desafio simples. A maioria das autoras da primeira metade do século XX produziram sob pseudônimos ou migraram para outros mercados como ilustração, design e artes visuais. Na contracultura as autoras produziram muito material em revistas underground de natureza perecível e com dificuldade de catalogação e somente com a cultura de conexão que conseguimos ter uma noção do grande contingente de autoras que decidiram se expressar por meio das histórias em quadrinhos.

Conceição Cahú é uma exceção no que se refere a catalogação das obras, uma vez que a artista possui um memorial em sua homenagem em Floresta, Pernambuco, mas cabe aos pesquisadores garimpar e traçar um panorama das autoras das histórias em quadrinhos. Em outros países como o Japão temos uma produção feminina fartamente documentada, mas no Brasil a realidade estamos em pesquisas de estágio inicial.

Conceição Cahú representa o humor feminino nos quadrinhos no Brasil. É um humor que não possui receio de apresentar suas referências. Ao anunciar que seu trabalho faz uma homenagem ao Carlos Zéfiro, a autora subverte e se posiciona acerca do consumo feminino da sua geração acerca da pornografia, da qual foi majoritariamente capitaneado pelos catecismos eróticos de Zéfiro.

É importante frisar que Uma História de Amor possui uma história comum, com desenvolvimento e final conservador, que reflete em grande parte as histórias cotidianas da sociedade brasileira. O diferencial consiste no senso de protagonismo ao impor o uso da camisinha, de não temer o machismo do personagem por ser uma capoeirista, a ironia e o grotesco do homem e o pênis como um ser de vida própria são marcas de humor que não são comuns nos quadrinhos feitos por homens. 


\section{REFERÊNCIAS}

CAHÚ, Conceição. In: Uma História de Amor. Piracicaba. Salão de Humor de Piracicaba,2018.http://salaointernacionaldehumor.com.br/sem-categoria/19o-salaode-humor-de-piracicaba-1992/ Acesso em: 15 de Ago. 2018.

EISNER, Will. Quadrinhos e arte sequencial 4ª̀. ed. - São PAulo: Editora WMF Martins Fontes, 2010.

HILDE Weber. In: ENCICLOPÉDIA Itaú Cultural de Arte e Cultura Brasileiras. São Paulo: Itaú Cultural, 2018. http://enciclopedia.itaucultural.org.br/pessoa23325/hildeweber. Acesso em: 15 de Ago. 2018. Verbete da Enciclopédia. ISBN: 978-85-7979-060-7

MAZUR Dan, DANNER Alexander. Quadrinhos - História Moderna de uma Arte Global. São Paulo.WMF Martins Fontes, 2014.

MCCUBBIN, Laurenn. The not-so-secret history of comics drawn by women Artigo publicado em:https://www.theguardian.com/books/2016/jan/10/women-comicsnot-so-secret-history. Acesso em 2018

ROBBINS, Trina. Woman in comics - An introductory Guide. Vermont. National Association of Comics Art Educators. Artigo publicado em www.teachingcomics.org. Acesso em 2018.

VERGUEIRO, Waldomiro. Panorama das histórias em quadrinhos no Brasil. São Paulo: Peirópolis, 2017. 


\section{ANEXOS}

Fig.o1. Fonte: (Salão de Humor de Piracicaba: 2018)

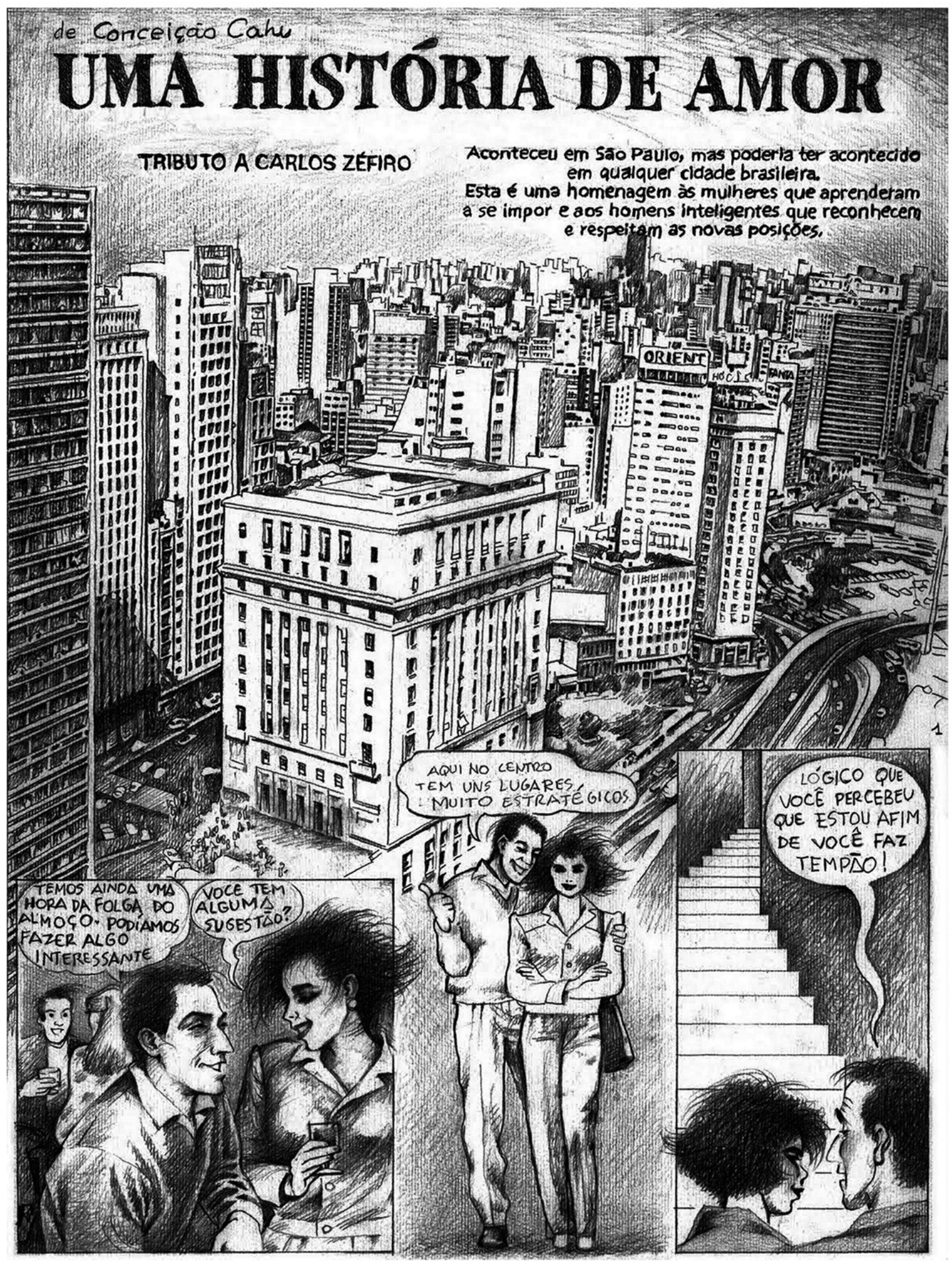


Fig.o2. Fonte: (Salão de Humor de Piracicaba: 2018)
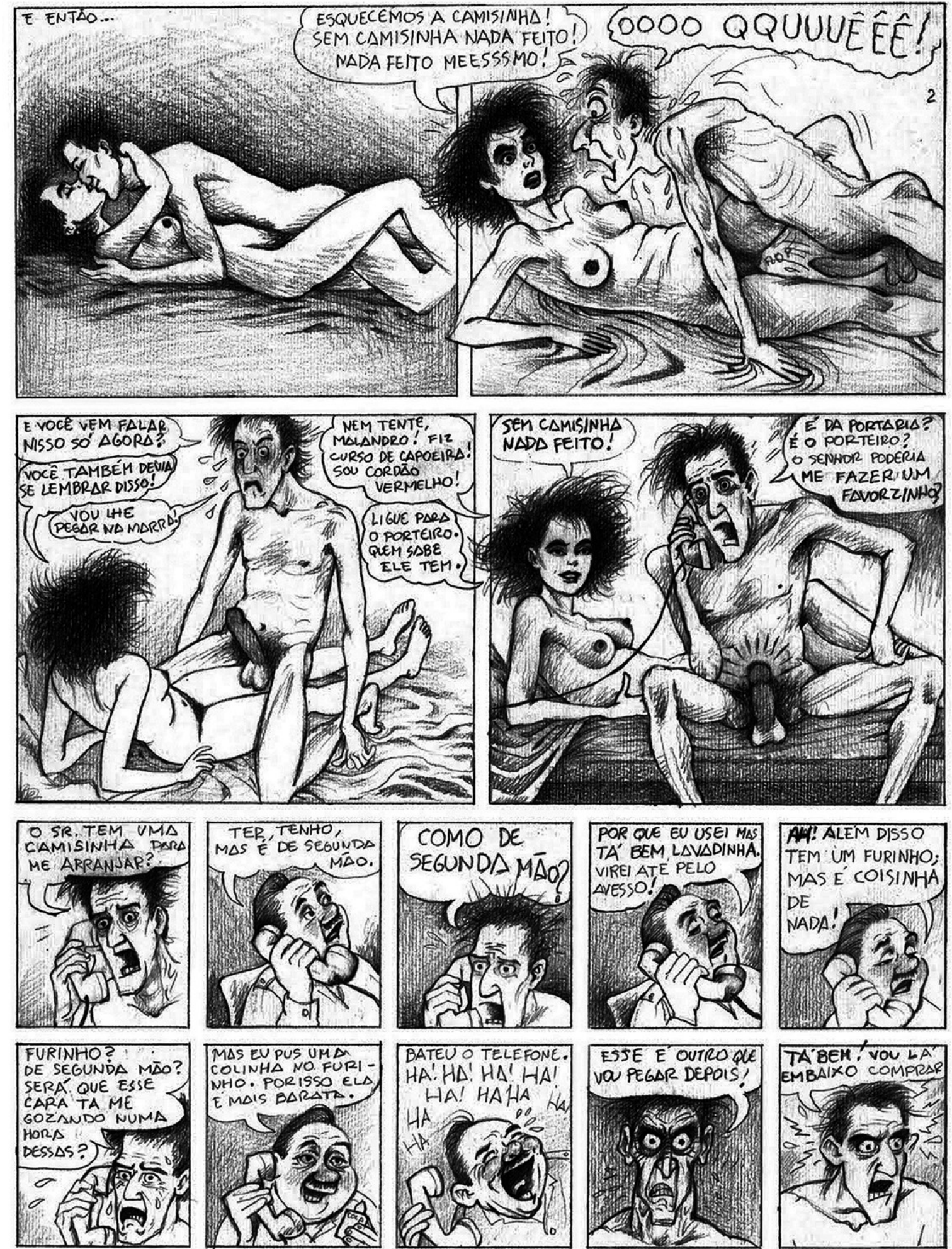
Fig.03. Fonte: (Salão de Humor de Piracicaba: 2018)

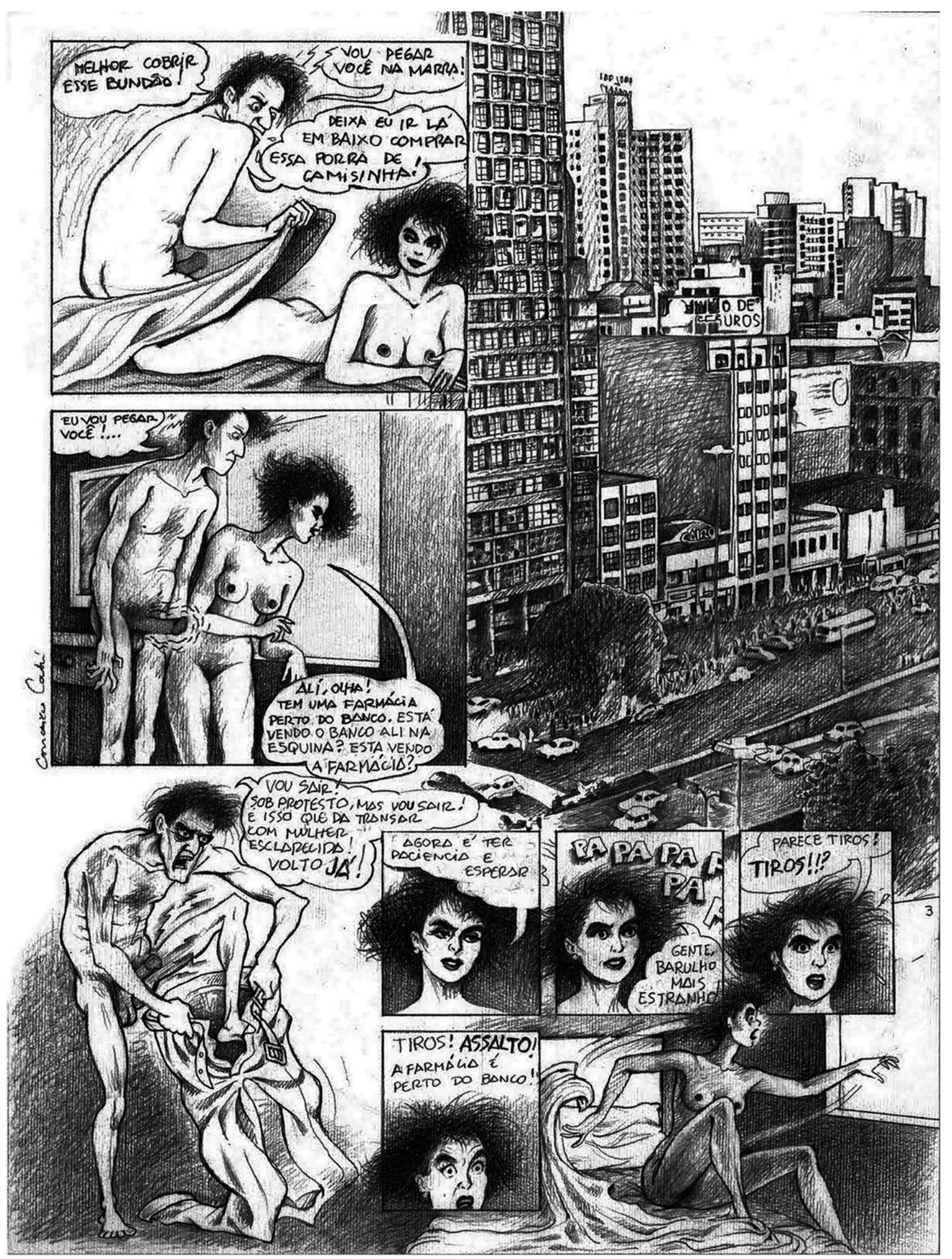


Fig.04. Fonte: (Salão de Humor de Piracicaba: 2018)

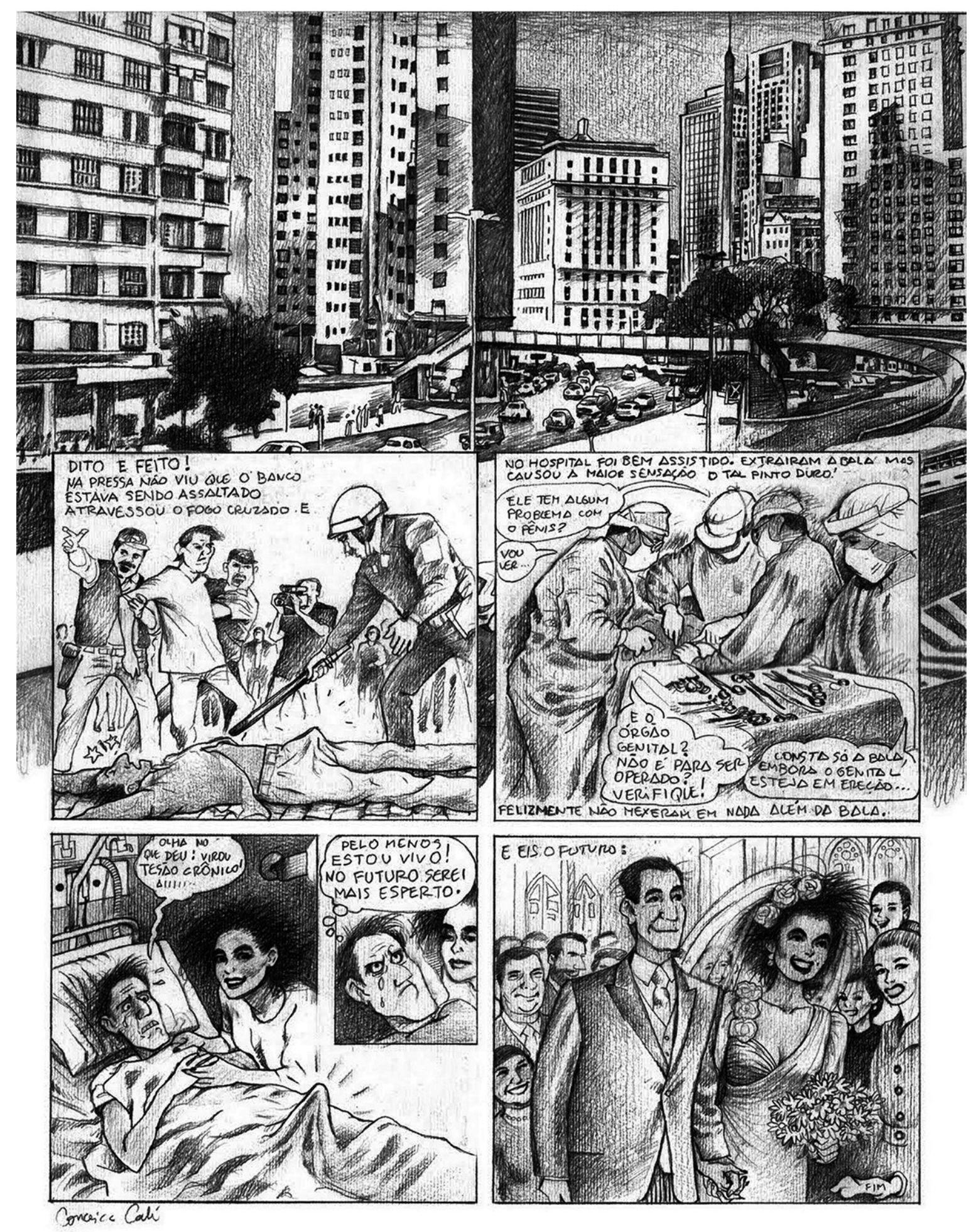


Fig.05. Fonte: (Salão de Humor de Piracicaba: 2018)
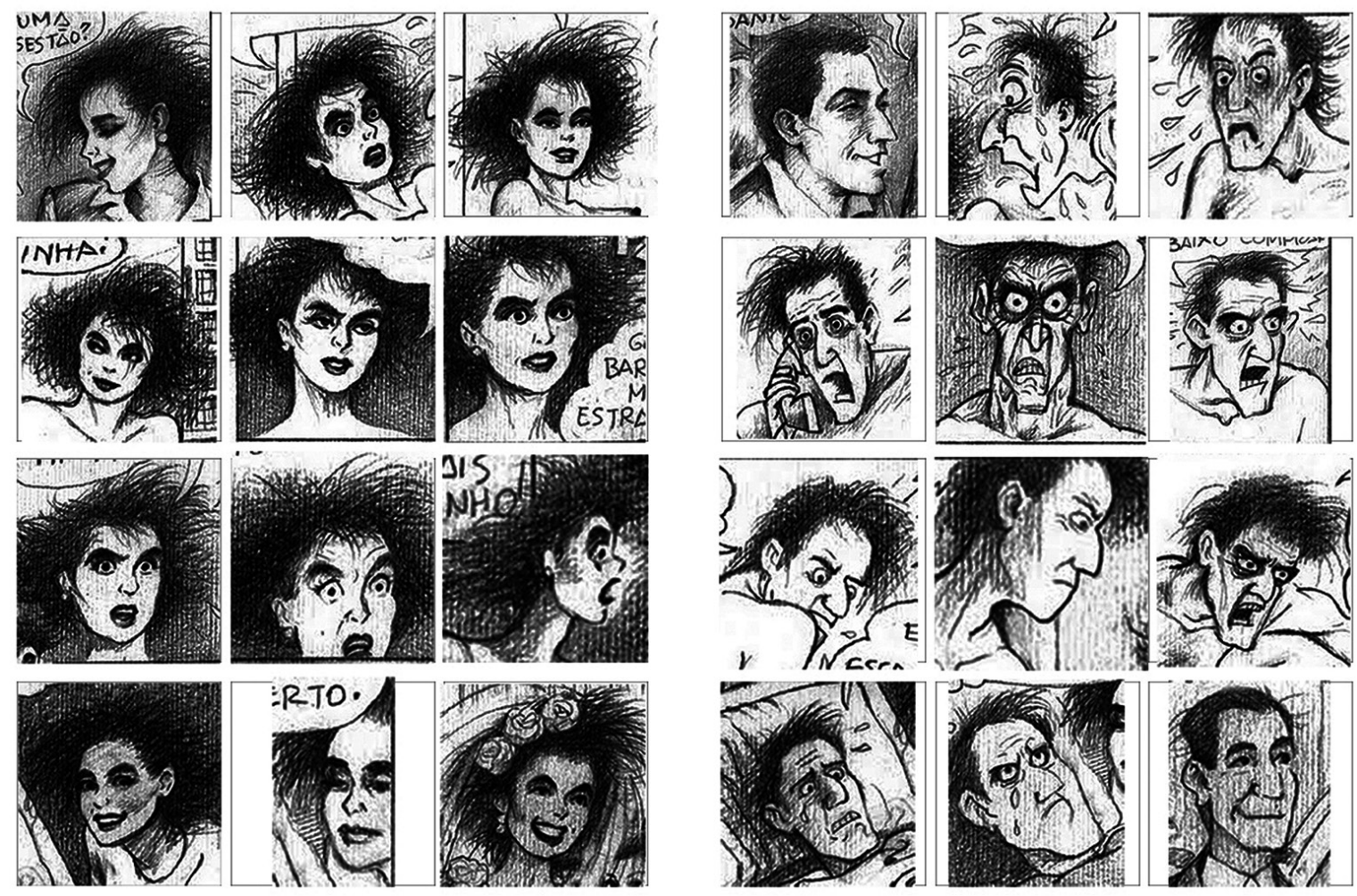
Fig.o6. Fonte: (Salão de Humor de Piracicaba: 2018)
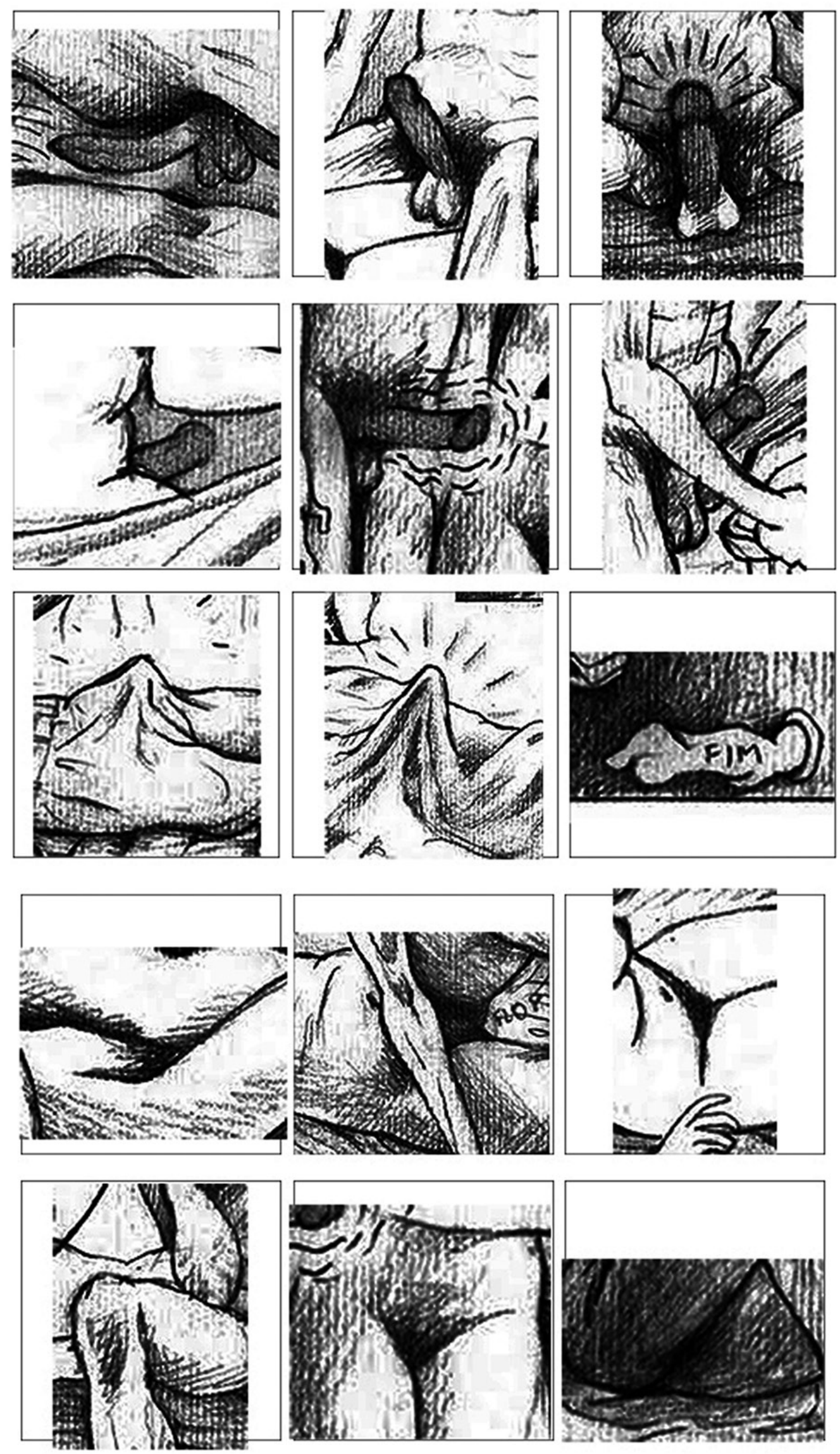